\title{
Feasibility study of recycled tire powder in construction blocks cement to decrease environmental pollution (a case study: Ahvaz, Iran)
}

\author{
Mohsen Eslami ${ }^{1}$, Farzaneh Fakeri Raof ${ }^{2 *}$, Mohammad Jorjor Zadeh ${ }^{3}$ \\ ${ }^{1}$ Master's Degree student in environmental pollution, Islamic Azad University, Khuzestan, Iran \\ $2 \mathrm{PhD}$ degree in environmental Science, Science committee of Islamic Azad university, Khuzestan, Iran \\ 3 Master's Degree in civil engineering, Science committee of Islamic Azad University, Ahvaz, Iran
}

\begin{abstract}
Today, retrieval and optimal use of exiting recourses and environmental protection is in view of serious attention of the development in the world. Approximately 300 thousand tons of old tires in the country has caused environmental pollution. Recycling of waste tires is completely different to which is done in our country. Unfortunately recycling scrap tires has not favorable growth in our country. Millions of tires are discarded each year, and the scrap piles of rubber this creates pose serious environmental problems. Rubber tires also leach hazardous materials into the environment as they decompose. This study was performed in Ahvaz metropolitan. In this study there are 9 building blocks which had different percentages of rubber powder as filling materials. Pressure test done on these blocks. The result of the stress test on the samples compared with the result of the stress test on the main samples. The comparison showed that by adding $10 \%$ of rubber powder instead of filler material in the process of preparing the block, there was no change in compressive strength. Therefore this block will be replaced by blocks used in construction industry. At least some of the environmental hazards caused by incorrect tire were buried as were recommendation to improve.
\end{abstract}

Keywords: Rubber powder, Block, Construction, Compressive strength, Environmental, Ahvaz 


\section{Introduction}

Environment is defined as the surroundings in which the organism lives. The environment may be the physical environment, the chemical environment or the biological environment. Thus, the environment has two components abiotic and biotic. The abiotic environment includes the air (atmosphere), water (hydrosphere) and land (lithosphere). The biotic environment includes the plants, animals and the microbe's.Organisms are dependent on the environment to fulfil their needs, man is also constantly interacting with the environment in order to fulfil his needs. These needs include the basic needs of oxygen, food and shelter in addition to the social needs like entertainment, medicines, etc. The things that man requires for his survival and comfort are called the resources. The environment is a reservoir of resources. For survival of man. It is very important environment. Maintaining the natural resources of the environment and their careful use is called conservation. The conservation of environment involves the conservation of the natural resources. Millions of tires are discarded each year, and the scrap piles of rubber this creates pose a serious fire hazard. Rubber tires also leach hazardous materials into the environment as they decompose. While rubber mulch is often touted as being a permanent mulch material, rubber is like any other organic material in that it does break down when subjected to sunlight, bacteria and fungi. As it decomposes, the chemicals in the rubber leach into the soil and nearby water sources. Many of these chemicals, as well as heavy metals, are dangerous to plants, soil and aquatic system. The recovery process and the optimum use of recourse and attitude to environmental protection seriously what's the national attention at application development recovery of scrap tires are seriously thinking of 70 years ago was established the countries of west. Parallel to the foundation and development of the tire industry. This days the idea of recycling scrap tires for various causes over $60 \%$ savings in the use of raw materials were. This recovery will be different use the coating

Recebido: dia/mês/ano Aceito: dia/mês/ano for powder and prepared reclaimed, recycled and reused as a raw material in the manufacturing of these material is rubber. Recycled rubber, plastic, paper and etc. in developing countries do not have the technology and raw materials is an important issue and not to pay attention.[1]According to the European association of tire recycling, the tire used in 2003 in European had reached 2.6 million ton. $62 \%$ of the used tires instead of buried in a tire storage sites were used for other purpose, So that $25 \%$ of it for energy production, $25 \%$ of it for recycle material and $12 \%$ of it to recap was used. [2] The road transport industry, which accounted for $80 \%$ of the country transport, is inevitable relationship with the countries tire industry. The accumulation of scrap tires in the environment as one of the greatest threats to the environment protection. [3]A large amount of rubber produced in the world. For example 3.6 (MT) tires produced annually in the U.S. The size of tires in the environment and burial is not possible and should these materials be recycled. Tire for improving the properties of concrete used. Adding rubber to concrete results in improved mechanical and dynamic properties of concrete. For example absorb more energy, better formability and better resistant to cracking.[4] With an overview of the country tire manufactures an tire imports to the conclusion that approximately 300 thousand tons of old tires in the country has caused environmental pollution and loss of biological life. Recycling of waste tires is completely different to what is done in our country. Unfortunately recycling scrap tires in our country is not favorable growth. recycling industrial tires only to activities and production of rubber powder and coating industry limited. In Iran, about 8 million ring used tires annually. The scrap tires can help to meet the needs of the industry the reuse them prevent environmental contamination [5] including significant losses every year due to the number of cars on the roads is produced rubber is worn out car.Smooth wheel is dangerous for the public and private vehicles and should not be used. On the other hand waste recovery such as those that are effective in preventing the waste of resources. Waste 
reduction, waste separation and recovery of the damages that they cause the return to the production cycle again. In addition, the product, the raw material for many industries such as flooring, all kinds of reinforcement and color replacement,asphalt, concrete and as the primary fuel for the furnace and raw material is rubber, etc Has application. and many applications inside and outside the country.Meanwhile,rubber recycling industry is highly regarded in the world because of the value of goods produced,also many large companies are professional on this industry and investment. Life tire recycling industry is low in Iran. Iran is a very broad field of activity for new artisans. Due to the properties of rubber and rubber powders are many significant applications. That these applications are being developed in our country. Unfortunately there are no accurate statistics on the amounts of waste tires the global value of scrap tires more than ten million tons per year is estimated.[6]

\subsection{Stockpile and legal dumping}

Tire stockpiles create a great health and safety risk. Tire fires can occur easily, burning for months, creating substantial pollution in the air and ground. Recycling helps to reduce the number of tires in storage. An additional health risk, tire piles provide harborage for vermin and a breeding ground for mosquitoes that may carry diseases. Illegal dumping of scrap tires pollutes ravines, woods, deserts, and empty lots; which has led many states to pass scrap tire regulations requiring proper management. Tire amnesty day events, in which community members can deposit a limited number of waste tires free of charge, can be funded by state scrap tire programs, helping decrease illegal dumping and improper storage of scrap tires. Unfortunately, tire storage and recycling are sometimes linked with illegal activities and lack of environmental awareness [7]

\subsection{Landfill disposal}

Tires are not desired at landfills, due to their large volumes and $75 \%$ void space, which quickly consumes valuable space.[8] Tires can

Recebido: dia/mês/ano Aceito: dia/mês/ano trap methane gases, causing them to become buoyant, or bubble to the surface. This 'bubbling' effect can damage landfill liners that have been installed to help keep landfill contaminants from polluting local surface and ground water.[9]Shredded tires are now being used in landfills, replacing other construction materials, for a lightweight backfill in gas venting systems, leachate collection systems, and operational liners. Shredded tire material may also be used to cap, close, or daily cover landfill sites.[10] Scrap tires as a backfill and cover material are also more cost-effective, since tires can be shredded on-site instead of hauling in other fill materials. Tires can be reused in many ways, although again, most used tires are burnt for their fuel value.

\section{Research carried out so far}

\subsection{Research carried out in Iran}

Experimental study of compressive Strength of concrete containing waste rubber powder was an article titled that presented by Moradi shaghaghI at 2012. In this study after analyzing the problems of inseparability rubber in the environment were discussed. Annually stated that over ten million rubber ring is out of the cycle. This study showed adding rubber powder to reduce the compressive strength of concrete and the intensity of the compressive strength of concrete in an amount quantity of cement powder replacement tires with lower water-cement ratio significantly decreases.[11]

Mechanical characterization of concrete article containing waste rubber powder was presented at 2008. In this article replacement truck tires wireless various amounts of cement in concrete. Based on the results obtain from this research are rubber powder concrete compressive strength and density of concrete were reduced. Replacing $12 \%$ of rubber powder instead of cement in concrete to reduce water absorption. But replacing $18 \%$ of rubber powder instead of cement increased water absorption in concrete. [12]

Rubber powder application was assessed at 2008. At this paper was uses a variety of rubber powder. Such as the use of waste rubber, powder rubber, rubber asphalt, concrete rubber, sports safe levels and coverage levels noted.[13] 
The use of crushed recycled rubber in asphalt road surface research curried off accepts at 2008. In this study, the use of recycled rubber in asphalt and the impact of roads and highway examined. In this paper, rubber asphalt advantage in durability, noise reduction, diameter reduction and improved resistance to frustration were investigated. Also in this paper experts disagree about the use of crumb rubber asphalt, rubber and new chemical substance instead of crumb rubber debate. [14]

\subsection{Foreign studies}

At united state demand by various industries tire rubber powder is about 5 thousand ton per year. [16]

The uses of rubber powder on the development level by lopersi were examined. In this study it was found that of the 1960, so far around the world especially in developing countries, using recycled rubber powder in civil cases to reduce environmental pollution. They checked out the possibility of using recycled rubber powder in asphalt for roads and highway in this study. Also in addition to successfully use a combination of this type, surface friction between the tires and the type of asphalt increase and when the car is slopping prevent sudden brakes. [15]

In the other study checked out the properties of rubber powder. And it was added to the rubber powder by $14 \%$ changes in the properties of concrete compressive strength does not create. And use the powder to the amount of concrete is permitted. [16]

In another paper examined improving carking in concrete using waste tires satisfactory result were observed. Crumb rubber from old tires was replaced to percentage of $3 \%$ and $7 \%$ by weight of sand. They concluded the use of crump rubber concrete is concrete increasing flexibility and reduction of area cracked, also causing cracks in the concrete later. [17]

Waste tire recycling concrete augmentative was other research. At this paper in addition to the environmental study of the utilization of natural rubber,concluded of concrete new technology helps production of concrete to the concrete ties researchers raised the possibility of the use of rubber powder in concrete.[18]

\section{The study area}

This research was carried out in Ahvaz, capital city of the province of Khuzestan located in the southwest of Iran, with an area of $238.8 \mathrm{~km} 2$. It consist of eight wards and has families from different socioeconomic backgrounds. Ahvaz has a population of 1.115.133. This municipality is characterizing by its industrial activity. [19]

Ahvaz is located 18 meters above sea level. According to the latest official statistics $32 \%$ of people are in the metropolitan. $35 \%$ of people lives in the suburbs. Ahvaz is the second city in terms of marginalizing. $51 \%$ of Iranian oil is produced in Ahvaz. There are some of the biggest factories in Ahvaz.

In terms of population, Ahvaz is seventh in Iran. Also Ahvaz is an important transit because by way of land, air, rail land. Other parts of the country are connected to the main ports in Iran, like Abadan, Khoramshahr, Mahshahr. The most important environmental problem depended to population growth.

\section{Methodology}

\subsection{Construction method of block}

To building block used to construct standard. This standard number is 1-70 and 270. This standard belong to the standard of the institute of standard industrial research of Iran.Also these standards are about in the case of hollow cement blocks. In this method, cement, water, mineral sand and, specific volcano sand with a specific ratio within the mixer are mixed. After that, mixed material were poured in production machine to product building blocks. The material in this device formed like block. After that the block dried in open air. Block drying time depended to the season and weather conditions. After drying the block prepare for market. In this study 9 different models of blocks with different properties had to be built to determine the best type with no change in compressive strength. This 9 model blocks have different percentage of materials between recycled rubber powder and mineral sand. By the way, block model 
was prepared according to the standard method 1-70. Now there are 10 blocks obtained with different percentage of materials is available.

\subsection{Naming blocks}

Prevent interference blocks were separated by Latin letters, Because of from and shape of blocks are the same. Block was named $((\mathrm{A}))$ was sample standard, that build by 1-70 method. Then, the blocks were transported to the laboratory workshop and prepared to pressure test.

\subsection{Capping}

In the process of preparing the block edges are not smooth. For obtain the best and accuracy result on the pressure test should be smooth blocks edges. So by plaster all surfaces are polished blocks except empty place. This process named capping. (fig1)

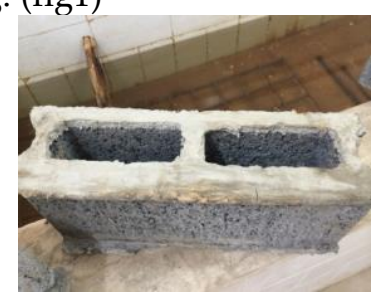

Fig. 1. Capping

\section{4 pressure test}

After that block was moved to workshop for pressure test. Each block individually by tested. The maximum tolerated load was recorded for each block.Hydrolytic jack was used to test pressure. (fig2)

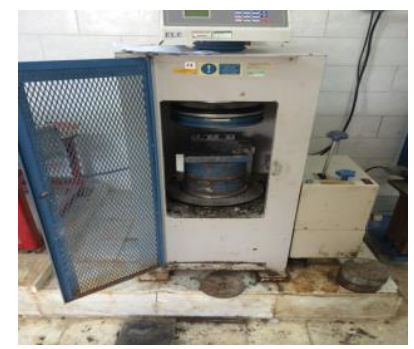

Fig. 2. Hydrolytic jack

The table (4-1) showed that 9 prepared blocks at workshop with how much the percentage of rubber powder instead of mineral sand replaced.

Table (4-1) that prepared blocks at workshop with how much the percentage of rubber powder instead of mineral sand replaced.

\begin{tabular}{c|c|c|c|c|c|}
\hline Row & block & cement (\%) & specific volcano sand(\%) & mineral sand(\%) & rubber(\%) \\
\hline 1 & A & 11 & 55 & 0 & 34 \\
\hline 2 & B & 11 & 55 & 5 & 29 \\
\hline 3 & C & 11 & 55 & 10 & 24 \\
\hline 4 & D & 11 & 55 & 13 & 21 \\
\hline 5 & E & 11 & 55 & 16 & 18 \\
\hline 6 & F & 11 & 55 & 17 & 17 \\
\hline 7 & G & 11 & 55 & 18 & 16 \\
\hline 8 & H & 11 & 55 & 21 & 13 \\
\hline 9 & I & 11 & 55 & 24 & 10 \\
\hline 10 & J & 11 & 55 & 34 & 0 \\
\hline
\end{tabular}

4.5 The combination of block components
Diagram (4.1) showed, the combination of block components. 


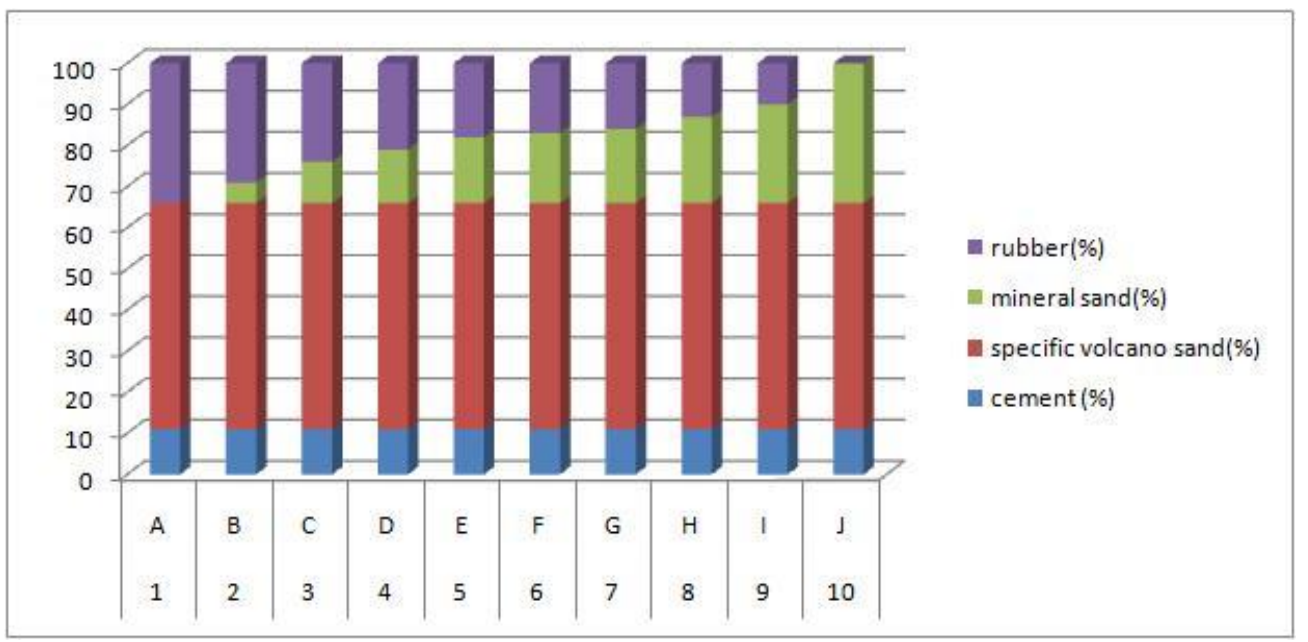

Diagram (4-1) the combination of block component.

In this graph is clear, the percentage of cement and specific volcano sand in all the samples was unchanged, also different amount of waste rubber powder was replaced with different amount of mineral sand

Table (4-2) showed the weigh and pressure test result of samples

Table (4-2) the weigh and pressure test result of samples

\begin{tabular}{c|c|c|c|c|c|c|}
\hline Row & block & Total surface $(\mathrm{cm} 2)$ & Weight $(\mathrm{gr})$ & Specific weight $(\mathrm{gr} / \mathrm{cm} 2)$ & Maximum forced $(\mathrm{kg})$ & Presuure resistant $(\mathrm{kg} / \mathrm{cm} 2)$ \\
\hline 1 & A & 156.9 & 6410 & 1.75 & 3070 & 12 \\
\hline 2 & B & 157.6 & 4610 & 1.3 & 1370 & 5 \\
\hline 3 & C & 148.9 & 5980 & 1.78 & 1200 & 5 \\
\hline 4 & D & 150.3 & 6000 & 1.78 & 1450 & 6.4 \\
\hline 5 & E & 150.9 & 6020 & 1.68 & 1540 & 7.2 \\
\hline 6 & F & 153.3 & 6080 & 1.78 & 1710 & 7.9 \\
\hline 7 & G & 157.1 & 6140 & 1.67 & 1820 & 8.4 \\
\hline 8 & H & 157.3 & 6250 & 1.74 & 2010 & 9 \\
\hline 9 & I & 155.2 & 6330 & 1.69 & 2070 & 10.6 \\
\hline 10 & J & 153.5 & 6370 & 1.86 & 3040 & 12 \\
\hline
\end{tabular}

Total surface is all levels of each block assuming that blocks are without any empty space. At diagram of (4-2) showed that dependence compressive strength and sand mineral. Diagram (4-2): That dependence compressive strength and mineral sand.

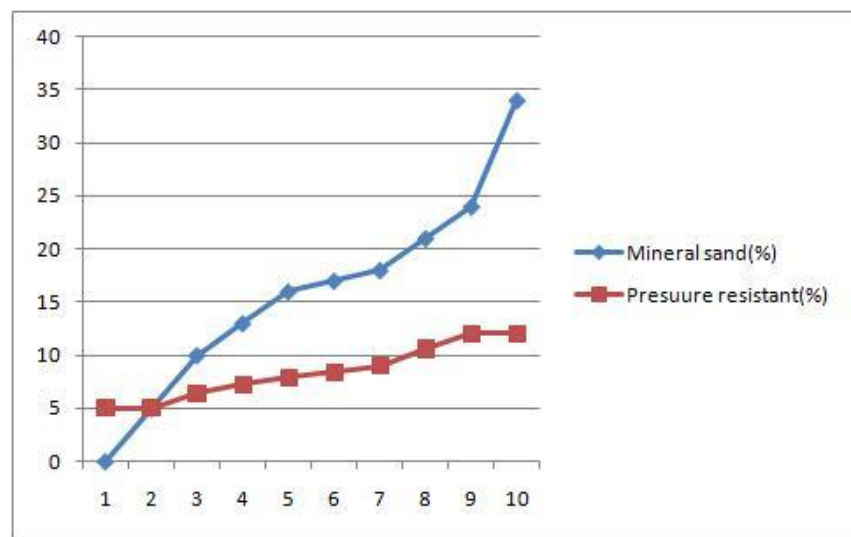

Diagram (4-3) showed that dependence compressive strength and different percentages of rubber powder. 


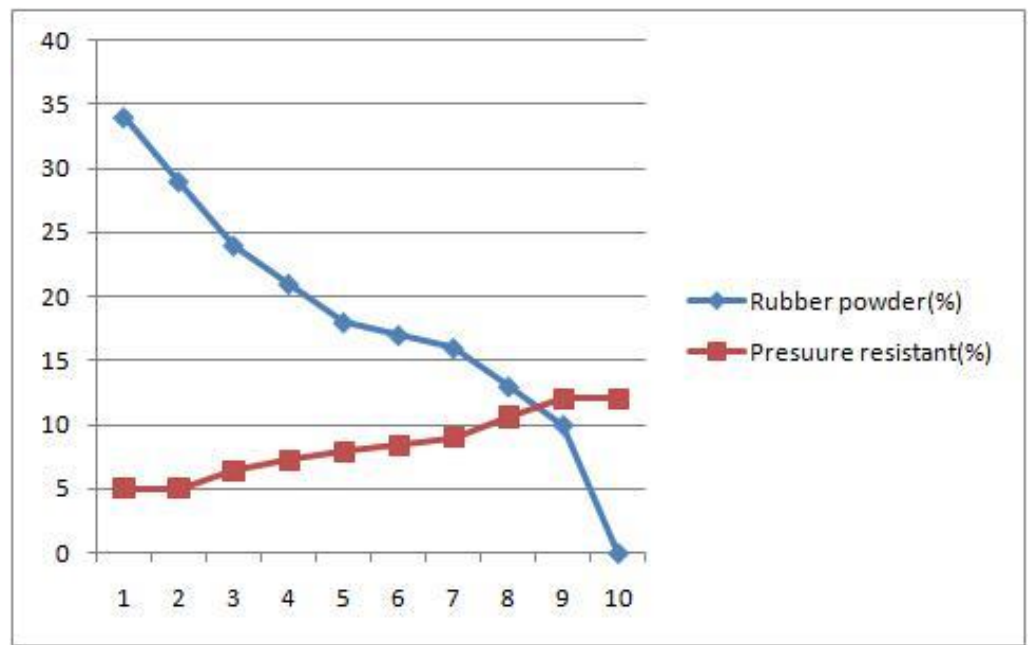

Diagram (4-3) That dependence compressive strength and different percentages of rubber powder.

\section{Conclusion}

According to test result were clear resistance samples containing different amount of rubber powder that instead of mineral sand that is if $10 \%$ of rubber powder is a combination of addition block change is not observed in compressive strength. The comparison showed that by adding $10 \%$ of rubber powder instead of filler material in the process of preparing the block, there was no change in compressive strength. Therefore this block will be replaced by blocks used in the construction industry. The alternative to such known, no change in the compressive strength of the block created. At this article from more than $21 \%$ Powder was added to the composition and block resistance at this amount $(21 \%)$ were reduce at the pressure test is clear diagram.

At table (4-2) showed that the weight of each block, the result of the weight Test, the specific gravity of each block, the maximum force and compressive strength.

(Diagrams 4-3 and 4-3) compressive strength decrease block with increase amount of rubber powder, and vice versa increased compressive strength. By increasing the percentage of mineral sand in this study it was found the compressive strength of the blocks does not change by adding small amount $(10 \%)$ of robber powder but block compressive strength decrease by increasing the amount of rubber powder compounds block. Also obvious block weight decreased by the compounds block in decrease of rubber powder, and vice versa block weight increase if increase percentage mineral sand.

In the present study, it was the color is dark block if added the percentage of mineral sand increase in the component of blocks.

\section{Suggestion}

- Feasibility recycled rubber powder production plant from recycled tires in Ahvaz.

- Facilities of the municipality to collect and transfer to the plant.

- Financial assistance from the found from Department of the environment to compensation for transportation costs, safety and similar cases.

- Management policies to determine and recycling of scrap tires.

- Export incentive for bicycler's of recycling tires and exporters of rubbers powder.

- Management practices to determine the politicized and implementation of recycling scrap tires.

- Given the encouraging expert for recycling scrap tires and exporter's powder, rubber and products.

- Motivate and encourage craftsmen for use the recycling powder and understanding the issues. 


\section{REFERENCES}

Haghighat khah, S., (2011). Functional and economic advantage of using rubber powder. Journal of rubber industry, paper recycling. No 59. p 198

Mokhtari mehr, M, (2004). The use of recycled rubber and rubber powder at different part of rubber. Iran rubber journal. Special recycled rubber, No42, p150

Jafari,J,(2011),. Check the rubber recycling industry and its impact on the environment and its solution in Iran and the other countries. Journal of rubber industry, paper recycling. No 59. p 20

Gerami, M.Bashiri, E,.Thaghdisi, M.H, Siahpolo, N,.(2011). Some features of concrete containing rubber powder, the first national conference of the concrete industry.

Functional and economic advantage of using rubber powder. Journal of rubber industry, paper recycling. No 59.,p 189

Mostophinezhad, D. Mohammadpour, B. Aminzade, H. Taghizade, A.(1994). Second international conference on concrete and development.

http://www.bbc.co.uk/news/uk-englanddevon-17195524

Agrawal, S.L.; Ameta, R.; Dasgupta, S.; Mukhopadhyay, R.; Deuri, A.S.; Ameta, Suresh C.; Ameta, Rakshit (2008). "An overview of rubber recycling". Progress in Rubber, Plastics and Recycling Technology 24: 73-112

In a 2003 report cited by the U.S. EPA, it is stated that markets ("both recycling and beneficial use") existed for $80.4 \%$ of scrap tires, about 233 million tires per year. Assuming $22.5 \mathrm{lbs}$ per tire, the 2003 report predicts a total weight of about 2.62 million tons from tires

$22.5 \mathrm{lb}$ working figure retrieved on 20 February 2010 from: http://www.rma.org/scrap_tires/scrap_tire_ markets/scrap_tire_characteristics/
Moradi SHaghaghi,t. Mohammadpour, B. Aminzade,H. Taghizade,H. (2011) Experimental investigation of the compressive strength of concrete containing waste rubber powder. Third national conference on earthquake engineering.

Behfarnia, K. Hassanzade, M. Etemadi, M. Azim far, F. (2009). Mechanical check of concrete containing rubber powder. The first national conference of the concrete industry.

Dashtianeh, Z. (2005). Aplication of rubber powder. Iran rubber journal. Special recycled rubber, No42, p140

Soltani.S. (2009). The use of rubber powder in asphalt main road. special recycled rubber,.No42, p112

Lo Persti, D. Notimgham Transportation Engineering Center.." Construction and Building Materials "49(2013)Univerciry of Notinghom.uk863-881

Pelisser, F. Zavarise, N. Arene Longo,T. Bernardin, A,M. (2011)." Journal of cleaner production "Page 757-763

CONCRETE: 1ST" International Conference on Sustainable Materials "2007_ICOMS 2007 911 June

Sandrolini. J. lonasrafhy. P. Wiktoria. M. (2010)"Environmental impact of Recycling Rubber in light fill application ": Summery \& Evaluation of Existing of

Monavari, s.m. Omrani. Gh,A. KarbasitA. Fakheri Raof. F"(2011) the effect of socioeconomic parameters on household solid-wast generation composition in developing countries (a case study: Ahvaz, Iran)".Springer Science 